\title{
HISTORIA DE LA FEDERACIÓN DE OBREROS DE LA INDUSTRIA DEL GAS, ELECTRICIDAD Y SIMILARES DE ESPAÑA Y DE SU ÓRGANO DE EXPRESIÓN, LA TURBINA*
}

\author{
History of the Spanish Federation of the Gas, Electricity and similar industries \\ Workers and its newsletter, La Turbina.
}

\author{
Mercedes Fernández-Paradas \\ Universidad de Málaga \\ paradas@uma.es \\ https://orcid.org/0000-0002-3049-0907 \\ Nuria Rodríguez-Martín \\ Universidad Complutense de Madrid \\ nuriarod@ucm.es \\ https://orcid.org/0000-0003-0179-7392
}

Recibido: 06-07-2020 - Aceptado: 09-02-2021

\begin{tabular}{|c|c|}
\hline lo/Citation: & $\begin{array}{l}\text { Copyright: (C) HISPANIA NOVA es una revista } \\
\text { debidamente registrada, con ISSN 1138-7319 y Depósito }\end{array}$ \\
\hline $\begin{array}{l}\text { Mercedes Fernández-Paradas y Nuria Rodríguez-Martín, } \\
\text { "Historia de la Federación de Obreros de la Industria del }\end{array}$ & $\begin{array}{l}\text { Legal M 9472-1998. Los textos publicados están -si no se } \\
\text { indica lo contrario- bajo una licencia Reconocimiento-Sin } \\
\text { obras derivadas } 3.0 \text { España de Creative Commons. Puede }\end{array}$ \\
\hline $\begin{array}{l}\text { Gas, Electricidad y Similares de España y de su órgano de } \\
\text { expresión, La Turbina", Hispania Nova, } 20 \text { (2022): } 1 \text { a } 26 .\end{array}$ & $\begin{array}{l}\text { copiarlos, distribuirlos y comunicarlos públicamente } \\
\text { siempre que cite su autor y la revista y la institución que } \\
\text { los publica y no haga con ellos obras derivadas. La licencia }\end{array}$ \\
\hline DOI: https://doi.org/10.20318/hn.2022.6434 & $\begin{array}{l}\text { completa se } \quad \text { puede } \quad \text { consultar } \text { en: } \\
\underline{\text { http://creativecommons.org/licenses/by-nd/3.0/es/deed.es }}\end{array}$ \\
\hline
\end{tabular}

Resumen: El sector del gas ha sido objeto de atención preferente dentro de la Historia económica, con especial énfasis en los empresarios, no así en los trabajadores. Con este trabajo pretendemos contribuir a subsanar este vacío historiográfico a través del análisis del contenido de la revista La Turbina, una publicación sindical y de orientación socialista publicada entre 1927 y 1933. En concreto, hemos estudiado sus características y la información que proporciona acerca de las principales preocupaciones de la Federación de Obreros de la Industria del Gas, Electricidad y Similares de España que la promovió. Las conclusiones de la investigación apuntan a la relativa debilidad de esta Federación, su posicionamiento favorable a los Comités Paritarios y los Jurados Mixtos, así como la severa crisis que la organización experimentó como consecuencia de las disputas 
con los anarquistas, que provocó el fin de la revista.

Palabras clave: Gas, electricidad, Federación de Obreros de la Industria del Gas, Electricidad y Similares de España, Unión General de Trabajadores, La Turbina, prensa obrera.
Abstract: The gas sector has received much attention by economic Spanish historians, particularly the role of employers and businessmen. However, there has been a lack of attention on workers of this sector. This paper aims to fill this historiographic gap, by examining the contents of an example of labour press, $L a$ Turbina, a socialist newsletter published between 1927 and 1933. Specifically, the paper examines the main characteristics of La Turbina alongside the information provided about the Spanish Federation of the Gas, Electricity and Similar Industries Workers and its concerns. Conclusions point, firstly how weakness this socialist Federation was despite the high number of workers employed in the energy sector in Spain at that time. Secondly, its support to the Comités Paritarios and the Jurados Mixtos, and finally, the crisis suffered by the organization as a result of the disputes with anarchists that eventually led to the end of the newsletter.

Keywords: Gas, Electricity, Spanish Federation of the Gas, Electricity and similar industries Workers, General Union of Workers, La Turbina, labour press.

\section{INTRODUCCIÓN}

El estudio de los trabajadores del sector del gas en España apenas ha merecido la atención de la historiografía, y ello a pesar de que las actividades de producción y suministro de esta energía han sido objeto de exhaustivo análisis desde el campo de la Historia Económica, lo que ha dado lugar a una prolija producción historiográfica que, no obstante, se ha centrado preferentemente en el papel de los empresarios, desatendiendo sin embargo el estudio de los trabajadores del sector y de sus organizaciones. Tampoco desde el ámbito de la Historia Social, que desde los años 70 ha tenido en el estudio del movimiento obrero español una de sus señas de identidad, se ha cubierto esta carencia.

\footnotetext{
* Este texto forma parte de los resultados del Proyecto I+D de Excelencia "La industria del gas en España: desarrollo y trayectorias regionales (1842-2008)", HAR2017-82112-P, financiado por el Ministerio de Ciencia e Innovación y Fondos FEDER (UE). Las autoras agradecen las recomendaciones y sugerencias de los evaluadores anónimos, que han contribuido a mejorar el artículo
} 
Este trabajo se concibe, precisamente, como una contribución para remediar en parte este vacío historiográfico al que nos referimos. Para ello, nos hemos centrado en la información proporcionada por una publicación sindical, La Turbina. Revista de la Federación Nacional de Obreros de la Industria del Gas, Electricidad y Similares de España, de orientación socialista, que fue publicada entre 1927 y 1933. El análisis de la prensa obrera es esencial para el estudio de la historia del movimiento obrero y de sus organizaciones, por ser un elemento de organización fundamental, según señaló el propio Manuel Tuñón de Lara ${ }^{1}$. En este sentido conviene destacar que la publicación que es objeto de nuestro análisis es una fuente inédita, hasta el punto de que no aparece recogida ni referenciada en los apartados dedicados a la prensa obrera en la exhaustiva y completísima obra de María Cruz Seoane y María Dolores Sáiz, Historia del periodismo en España. Tampoco se encuentran datos sobre la misma en la completa monografía Prensa Obrera en Madrid, 1855-1936, que Santiago Castillo y Luis E. Otero Carvajal editaron en $1987^{2}$.

En los años en los que se publicó -1927 a 1933-, la prensa obrera vivió un periodo desigual. Los años que se corresponden con la Dictadura de Primo de Rivera y hasta la proclamación de la Segunda República en abril de 1931, algunas publicaciones desaparecieron, optaron por "marginarse", particularmente las anarquistas y comunistas $^{3}$, un reflejo más de la presión que sufrían estas organizaciones. La prensa

\footnotetext{
${ }^{1}$ Manuel Tuñón de Lara, "Prensa obrera e Historia contemporánea", en Prensa obrera en Madrid, 18551936, ed. por Santiago Castillo y Luis E. Otero Carvajal (Madrid: Comunidad de Madrid-Revista ALFOZ, 1987), 25.

${ }^{2}$ Un capítulo inserto en la monografía escrito por Carlos Dorado Fernández y dedicado a las publicaciones obreras madrileñas publicadas entre 1923 y 1936 que se han conservado en la Hemeroteca Municipal de Madrid, contiene un "Índice cronológico" en el que aparece La Turbina en el año 1929, por tanto, no se conservan en esta institución todos los números de la publicación. Véase Carlos Dorado Fernández, "Publicaciones obreras madrileñas, de 1923 al 18 de julio de 1936, en la Hemeroteca Municipal de Madrid, en Prensa obrera en Madrid, 1855-1936, ed. por Santiago Castillo y Luis E. Otero Carvajal (Madrid: Comunidad de Madrid-Revista ALFOZ, 1987), 759.

${ }^{3}$ Tras el golpe de Estado de Primo de Rivera, la Confederación Nacional del Trabajo (CNT) pasó a la clandestinidad y el Partido Comunista de España (PCE) fue declarado ilegal a finales de 1923. Parte de la prensa anarquista optó por marginarse y desaparecieron cabeceras como Solidaridad Obrera, que dejó de publicarse entre 1924 y 1930, mientras otras se mantuvieron, como La Revista Blanca. Igualmente aparecieron nuevos órganos de expresión libertarios, como ;Despertad! (Vigo, 1928-1930), Horizonte (Elda) o Estudios (Valencia). Respecto a la prensa comunista, contaba con seis medios de propaganda al producirse el golpe de Primo de Rivera, destacando el semanario La Antorcha, editado en Madrid, que logró mantener su publicación durante la Dictadura. En agosto de 1930 se fundó Mundo Obrero. Sobre la prensa obrera durante la Dictadura de Primo de Rivera, pueden consultarse, entre otros, María Cruz Seoane y María Dolores Sáiz García, Historia del periodismo en España 3. El siglo XX: 1898-1936
} 
socialista capitalizó la colaboración del PSOE con la Dictadura, ocupando prácticamente todo el espacio informativo obrero ${ }^{4}$. Con la proclamación de la República, la prensa obrera anarquista y comunista vivió un momento floreciente. Baste señalar que solo en la región catalana se publicaron hasta 1936 más de cuarenta cabeceras libertarias y al menos 20 comunistas repartidas por todo el territorio nacional. También fue un momento de gran efervescencia para la prensa socialista, que no solo vio como experimentaba un gran crecimiento su principal portavoz, El Socialista, sino que se lanzaron nuevos títulos como Claridad, Democracia, Avance... Según el propio PSOE, en Madrid se editaban más de un centenar de semanarios, la mayoría por la Unión General de Trabajadores (UGT). Igualmente, queremos destacar que el marco cronológico en el que nos centramos -1927 a 1933- es particularmente interesante, puesto que es la etapa de plena madurez del movimiento obrero en España ${ }^{5}$.

Respecto a la evolución del sindicato socialista UGT al que pertenecía la Federación Nacional de Obreros de la Industria del Gas, Electricidad y Similares de España, fue un periodo ambivalente, marcado por la acomodación y colaboración de la organización con la Dictadura primorriverista tras el golpe de Estado de 1923, y la posterior ruptura que llegó en 1927, después del distanciamiento con el régimen iniciado a finales iniciado a finales de aquel año, tras la celebración del Congreso Extraordinario celebrado en los primeros días de octubre ${ }^{6}$. Al finalizar esta etapa, la Unión General tenía 1.347 secciones y 210.567 federados (julio de 1928), habiendo crecido el número de afiliados en algunas regiones, como el Levante, mientras en otras de fuerte

(Madrid: Alianza, 1996), 367-368, María Dolores Sáiz García, "Prensa comunista durante la Dictadura de Primo de Rivera: el proyecto de unidad sindical en 'La Antorcha', en La prensa de los siglos XIX y XX. Metodología, ideología e información. Aspectos económicos y tecnológicos: I Encuentro de Historia de la Prensa, ed. por Carmelo Garitaonandia Garnacho (Bilbao: Universidad del País Vasco, 1986), 245-262; y Santiago Castillo y Luis E. Otero Carvajal (ed.), Prensa obrera,...

${ }^{4}$ Véase María Cruz Seoane y María Dolores Sáiz García, Historia del periodismo, ..., 369.

${ }^{5}$ Francisco Sánchez Pérez, "El movimiento obrero antes de la guerra civil: el enfoque de Manuel Tuñón de Lara", Cuadernos de Historia Contemporánea, 30, (2008): 105-116. https://revistas.ucm.es/index.php/CHCO/article/view/CHCO0808110105A/6727 . La cifra de huelgas, huelguistas y jornadas de huelgas en España en los años 1910 a 1931, en José Luis Martín Ramos, Historia de la UGT. Entre la revolución y el reformismo, 1914-1931. (Madrid: Siglo XXI, 2008), s. pág. (Cuadro 1).

${ }^{6}$ Para el estudio de la UGT durante la Dictadura de Primo de Rivera resultan fundamentales las obras de Luis Martín Ramos, Historia de la UGT. Entre la revolución,...; Benjamín Martín, Los problemas de la modernización. Movimiento obrero e industrialización en España (Madrid: Ministerio de Trabajo y Seguridad Social, 1992), y José Andrés Gallego, El socialismo durante la dictadura, 1923-1930. (Madrid: Tebas, 1977). 
implantación, como Asturias o Vizcaya, el número de afiliados descendió de forma significativa $^{7}$. La ruptura, no obstante, tuvo efectos positivos en el número de ugetistas, ya que al finalizar el año 1930 el sindicato se acercaba a los 300.000 afiliados $^{8}$. Con la proclamación de la Segunda República, la fuerza de la UGT creció exponencialmente, aumentando el número de sus miembros de forma espectacular, pues a mediados de 1932 superó el millón de afiliados ${ }^{9}$.

Como ya se ha señalado más arriba, el objetivo de nuestra investigación es aportar información y conocimiento al estudio de las organizaciones obreras del sector energético español en los años previos al estallido de la Guerra Civil española, en este caso, a través del análisis de una organización sindical no estudiada hasta la fecha, la Federación Nacional de Obreros de la Industria del Gas, Electricidad y Similares de España. Hemos tratado de comprobar, ante todo, la importancia e implantación de dicha Federación en el país en relación con la fuerza laboral empleada en el sector gasista en España a lo largo del periodo de referencia.

Metodológicamente podemos destacar que, como ya hemos señalado, la principal fuente documental sobre la que se fundamenta nuestra investigación es la revista La Turbina, órgano de expresión de la Federación. Hemos procedido a realizar un vaciado sistemático de todos los números de la publicación para a continuación proceder al análisis de los contenidos. Además, se ha localizado y analizado documentación conservada en el Centro Documental de la Memoria Histórica, que nos ha servido para completar y contrastar la información recogida en la revista acerca de la escisión en la Federación.

Hemos recurrido también a otras cabeceras de prensa de la época. Desafortunadamente, en el Archivo de la Unión General de Trabajadores no se conserva

\footnotetext{
${ }^{7}$ El número total de afiliados a la UGT en 1922 era de 208.170. En el caso de la UGT asturiana, el número de afiliados cayó de 18.147 en ese año a 12.808 en 1928. La caída fue muy significativa en Vizcaya, donde el número de afiliados pasó en esos mismos años de 17.575 a 9.938. Cifras recogidas en José Andrés Gallego, El socialismo durante, ...,153, y en José Luis Martín Ramos, Historia de la UGT. Entre la revolución,..., 157.

${ }^{8}$ José Luis Martín Ramos, Historia de la UGT. Entre la revolución,..., 160.

${ }^{9}$ Sobre la UGT durante la Segunda República puede consultarse, entre otros, Manuel Redero San Román, Estudios de Historia de la UGT (Salamanca: Ediciones Universidad de Salamanca-Fundación Largo Caballero, 1992), y Marta Bizcarrondo, Historia de la UGT. Vol. 3. Entre la democracia y la revolución, 1931-1936 (Madrid: Siglo XXI, 2008).
} 
documentación sobre la Federación y su publicación ${ }^{10}$, y solo hemos podido localizar algunas informaciones en el Boletín General de la Unión General de Trabajadores. En el Archivo de la Fundación Pablo Iglesias hay material de la Guerra Civil que nos ha servido para constatar que la Federación continuó existiendo tras la severa crisis que sufrió en 1933. Antes de comenzar con el análisis, es necesario precisar que durante la Dictadura de Primo de Rivera- recordamos que la publicación comenzó a publicarse en 1927- la revista La Turbina fue objeto de censura previa.

\section{LA FEDERACIÓN NACIONAL DE OBREROS DE LA INDUSTRIA DEL GAS, ELECTRICIDAD Y SIMILARES DE ESPAÑA Y LA TURBINA}

La Federación Nacional de Obreros de la Industria del Gas, Electricidad y Similares de España fue constituida en 1924, como entidad dependiente de la Unión General de Trabajadores. Su sede fue fijada en la Casa del Pueblo de Madrid, en la calle Piamonte, $n^{0}$. 2. El número de afiliados que pagaron la cuota en el segundo semestre de 1926 fue de 1.856, a finales de 1929 fueron 3.522, en el primer trimestre de 1932 sumaron 4.972, un año después $5.397^{11}$, en agosto de 1933 fueron 7.538, cifra esta última que también incluye a quienes no estaban al corriente de las $\operatorname{cuotas}^{12}$. La implantación territorial también fue relativamente pequeña, a finales de 1926 tuvo sindicados en 15 municipios, a principios de 1933 en $34 .{ }^{13}$ En definitiva, se trató de una organización con una débil implantación, máxime si tenemos en cuenta que representaba a los trabajadores del sector eléctrico que por entonces estaba presente en casi todos los municipios.

En 1927 se publicó el primer número de La Turbina. En sus primeras páginas el Comité Nacional (El Comité), el órgano de dirección del sindicato, explicó los motivos de su creación. Entre ellos, dar a conocer la ideología del sindicato y poner en contacto a

\footnotetext{
${ }^{10}$ Véase Aurelio Martín Nájera y Antonio González Quintana, Fuentes para la Historia de la Unión General de Trabajadores (Madrid: Editorial Pablo Iglesias, 1988).

${ }^{11}$ La Turbina, $\mathrm{n}^{\mathrm{o}}$. 1, julio de 1927, nº. 6, julio de 1930, y n ${ }^{\circ} .10$, julio de 1933.

${ }^{12}$ Centro Documental de la Memoria Histórica (CDMH), P-S. Santander 0-141, Actas del V Congreso de la Federación Española de Agua, Gas y Electricidad, Acta en segunda sesión celebrada en la tarde del 12 de agosto, 1.

${ }^{13}$ La Turbina, $\mathrm{n}^{\mathrm{o}}$. 1, julio de 1927, y nº. 10, julio de 1933.
} 
la organización con sus militantes, manteniéndolos informados. Igualmente, se concebía a este órgano de prensa como un instrumento pedagógico ${ }^{14}$. Además, la publicación trató temas de actualidad para la organización, que son el principal objetivo de esta investigación. Se publicaron un total de 10 números de la revista entre los años 1927 y 1933, el primero en julio de 1927, el último seis años después ${ }^{15}$.

Respecto a su tirada ${ }^{16}$, solo disponemos de datos fragmentarios. Del número 4, correspondiente a marzo de 1929, se imprimieron 3.500 ejemplares; 6.000 del $\mathrm{n}^{\circ} .8$, de mayo de 1932, y 7.000, del $\mathrm{n}^{\mathrm{o}} .9$, de febrero de $1933^{17}$, es decir, en relativamente poco tiempo el número de ejemplares por número se duplicó ${ }^{18}$.

La Federación pertenecía a la Internacional de Servicios Públicos, a la que enviaba la revista, también a sindicatos homónimos integrados en la Internacional, en concreto de Bélgica, Francia y Suiza. Esto significa que, pese a su reducida tirada, la difusión de La Turbina trascendió el ámbito nacional.

Este estudio se interesa por los temas que concitaron mayor atención en la revista, vinculados con los momentos políticos en que se desarrolló la publicación, la Dictadura de Primo de Rivera, los gobiernos de Dámaso Berenguer y Juan Bautista Aznar y el primer bienio de la Segunda República, en relación a la política social. La Turbina mostró gran interés sobre diversos asuntos que están estrechamente vinculados

\footnotetext{
${ }^{14}$ La Turbina, $\mathrm{n}^{\mathrm{o}}$. 1, julio de 1927, 1-2.

15 Durante la Dictadura de Primo de Rivera en Madrid otras asociaciones obreras publicaron sus órganos de difusión. Sobre este tema, véase María Francisca Bernalte Vega, Antonio Fontecha Pedraza y José Carlos Gibaja Velázquez, "Cultura popular madrileña durante la dictadura: el mundo obrero socialista 1923-1930", en La sociedad madrileña durante la Restauración, ed. por Ángel Bahamonde y Luis Enrique Otero Carvajal, (Madrid: Comunidad de Madrid, 1989), 543. Este es el trabajo de referencia sobre las publicaciones obreras socialistas de Madrid durante la Dictadura de Primo de Rivera, que se completa con el de Carlos Dorado Fernández, "Publicaciones obreras madrileñas", 719-762, acerca de las publicaciones obreras madrileñas desde 1923 a 1936. Para la prensa socialista en esa etapa, es importante el estudio de María Dolores Sáiz García, "Prensa socialista durante la dictadura de Primo de Rivera", en Presse et pouvoir en Espagne, ed. por Paul Aubert y Jean-Michel Desvois (Madrid: Maison de Pays Ibériques-Casa de Velázquez, 1996), 139-150.

${ }^{16}$ En estos años no existía en España ningún organismo independiente para la verificación del control de las tiradas de la prensa periódica. Las cifras de ejemplares impresos las proporcionaban los propios editores de prensa, como es el caso.

${ }^{17}$ La Turbina: $\mathrm{n}^{\mathrm{o}} .9$, noviembre de 1929, 2; y, nº. 10, julio de 1933, 38.

$18 \mathrm{Si}$ consideramos todos los socios, incluidos los que no pagaban la cuota, en octubre de 1931 la Federación tenía 8.075, esto suponía el 1,2\% de los afiliados de la UGT. Boletín de la Unión General de Trabajadores, $\mathrm{n}^{\circ} .37$, enero de 1932.
} 
con la debilidad de la Federación a la que ya hemos aludido, su posicionamiento ante la Dictadura de Primo de Rivera y los gobiernos del primer bienio de la Segunda República, especialmente con relación a los Comités Paritarios y los Jurados Mixtos, las relaciones con los anarquistas $\mathrm{y}$, estrechamente vinculado con esto último, la crisis que la organización sufrió en 1932 y 1933.

\title{
UNA FEDERACIÓN DÉBIL Y CON POCOS AFILIADOS
}

El asunto de la debilidad de la organización se afrontó principalmente de dos maneras. La primera, mediante llamamientos a la afiliación ${ }^{19}$ y críticas a los trabajadores que no respondían positivamente, también a los que querían estar a bien con los patronos. La segunda consistió en requerimientos a los socios para que abonasen la cuota, proponiendo además que esta fuese mayor.

La escasa fuerza de la Federación se infiere del escaso número de afiliados y de municipios en los que tenía presencia, a los que hemos aludido más arriba. Fueron numerosos los llamamientos que se hicieron desde la revista para promover la sindicación. A este respecto, Joaquín Moya, en un artículo publicado en el $n^{\circ} 1$, titulado "Consecuencias", planteó las siguientes cuestiones:

\begin{abstract}
¿Es que creen estos equivocados que obrando de esa forma alcanzarán la confianza de arriba escalando mejores puestos? [...] ¿por qué en vez de acudir a malas artes y entretener el tiempo en retrasar vuestra emancipación no trabajáis en el seno de las
\end{abstract}

\footnotetext{
${ }^{19}$ La afiliación era baja en el ámbito socialista, esto se explica, en parte, por el reducido peso de los asalariados respecto del total de la población de Madrid que solo sumaba el 5\% de los habitantes en 1930. María Francisca Bernalte Vega, Antonio Fontecha Pedraza y José Carlos Gibaja Velázquez, "Cultura popular madrileña durante la dictadura: el mundo obrero socialista 1923-1930", en La sociedad madrileña durante la Restauración, ed. por Ángel Bahamonde y Luis Enrique Otero Carvajal, (Madrid: Comunidad de Madrid, 1989), 545. Los salarios de los trabajadores del sector de la energía estaban entre los más elevados de la industria en España en este periodo. En Madrid, donde existían grandes empresas del sector como Gas Madrid, S.A., A.E.G. Ibérica de Electricidad, Standard Eléctrica o Unión Eléctrica Madrileña, los sueldos de sus trabajadores cualificados se encontraban entre los más altos, con salarios diarios medios de entre 11,33 y 8,70 pesetas en el año 1930. Fernando Vicente Albarrán, "Los barrios negros: el Ensanche Sur en la formación del moderno Madrid (1860-1931)" (Tesis doctoral, Universidad Complutense de Madrid, 2011), 486, y Fernando Vicente Albarrán, "Los trabajadores manuales en el Madrid del primer tercio del siglo XX", en Las nuevas clases medias urbanas. Transformación urbana y cambio social en España, 1900-1936, editado por José María Beascoechea Gangoiti y Luis Enrique Otero Carvajal (Madrid: Catarata, 2015), 100-109.
} 
Agrupaciones donde se labora en beneficio de todos, siempre que se cumpla con el deber?

En la misma línea, Luis Martínez García, afiliado a la Sociedad de Gasistas y Electricistas de Almería escribió "Dice mal que en el siglo XX haya ni un solo obrero sin estar organizado" ${ }^{20}$. En el no . 2, de febrero de 1928, Jorge Unsaín, Presidente de la Federación, en "Apreciaciones", aludió al esfuerzo realizado por el Comité para contactar con los empleados de las industrias de agua, gas, electricidad y similares, solicitándoles su ingreso: "Y a pesar de todos los esfuerzos del Comité, son varios los que han dado la callada por respuesta”. También afirmó que a instancias suyas, se habían constituido secciones ${ }^{21}$ que no funcionaban por el reducido número de sus miembros. Señaló igualmente a modo de ejemplo, que había obreros en Madrid de dichas actividades que estaban afiliados a otras sociedades, cuando desde 1898 existía la Sociedad de Gas, Electricidad y Similares, destacada en la consecución de "muchas mejoras"22. En el mismo número, V. Marco Camilleri, Presidente de la Sección Gas Lebon, en "Cuatro notas y un resumen", vertió reproches contra los que no se afiliaban y criticaban al Comité y las secciones ${ }^{23}$. En ese sentido, Germán Calvo Lazolo, Vicepresidente de la Sección de Valencia, consideró que los obreros tenían un concepto equivocado acerca de las organizaciones obreras, al pensar que por el hecho de afiliarse inmediatamente llegarían las mejoras en las condiciones laborales, sin que hubiese represalias por parte de los jefes, apeló a la conciencia de clase que conllevaría la afiliación $^{24}$.

El llamamiento a la sindicación de las mujeres trabajadoras también apareció en las páginas de La Turbina. En el nº. 2, de febrero de 1928, V. Marco, en "Cuatro notas y un resumen", afirmó que las mujeres que trabajaban como mecanógrafas en una de las empresas de la Federación, se habían afiliado, poniéndoselas como ejemplo y

\footnotetext{
20 Joaquín Moya, "Consecuencias", La Turbina, no. 1, julio de 1927, 3-4. Luis Martínez García, "Por nuestra unión”, La Turbina, ${ }^{\circ}$. 1, julio de 1927, p. 18. Al respecto, también puede consultarse La Turbina, $\mathrm{n}^{\circ} .3$, septiembre de 1928, 1.

${ }^{21}$ Las secciones debían tener un mínimo de 10 miembros. Estatutos de la Federación de 1930.

${ }^{22}$ Jorge Unsaín, “Apreciaciones”, n'. 2, febrero de 1928, 2-3.

${ }^{23}$ V. Marco Camilleri, “Cuatro notas y un resumen”, La Turbina, $\mathrm{n}^{\mathrm{o}}$. 2, febrero de 1928, 6.

${ }^{24}$ Germán Calvo Lazolo, "Por la organización y por nosotros", La Turbina, n. 3, septiembre de 1928, 2021.
} 
destacándose su decisión, puesto que lo habían hecho “despreocupándose de las predicaciones y consejos de los de arriba y de sus allegados, han acudido presurosas a ingresar en la organización obrera, e incluso, dos de ellas había sido nombradas vocales de la Directiva",25.

En cuanto a las cuotas, en un artículo de Jorge Unsaín publicado en el $\mathrm{n}^{\mathrm{o}}$. 4, marzo de 1929, "Problema de suma importancia", $\mathrm{n}^{\circ} .4$, propuso, para disponer de más recursos económicos, la subida de la cuota de los afiliados al nivel de las de los compañeros de otros países ${ }^{26}$. Además, destacó el hecho de que en las sociedades obreras de Madrid era habitual el pago de 75 céntimos de peseta al mes ${ }^{27}$, cuando por entonces la contribución por afiliado de la Federación era de 0,45 pesetas por trimestre. En el $\mathrm{n}^{\mathrm{o}}$. 5, de noviembre de 1929, en el artículo titulado "Importante", que no fue firmado, se exhortó a que "las Secciones envíen la cotización con regularidad, rogamos a las que tengan algún trimestre al descubierto envíen la cantidad correspondiente" ${ }^{28}$. Se trata de un tema que también fue tratado en el $\mathrm{V}$ Congreso de la Federación que se celebró en agosto de 1933 en Madrid. Durante el mismo, Trifón Gómez, que intervino en representación de la UGT, defendió la necesidad de que fueran establecidas cuotas más elevadas ${ }^{29}$.

\section{EL DEBATE ACERCA DE LA COLABORACIÓN OBRERA CON LA DICTADURA PRIMORRIVERISTA Y LOS GOBIERNOS REPUBLICANOS}

El asunto que más atención concitó fue el de la participación de la Federación en organismos creados por el Gobierno, sobre todo en los Comités Paritarios de la Dictadura de Primo de Rivera, denominados Jurados Mixtos durante la Segunda República. El apoyo del Partido Socialista Obrero Español y la Unión General de Trabajadores hay que entenderlo en el contexto de su colaboracionismo respecto de la

\footnotetext{
${ }^{25}$ V. Marco Camilleri, “Cuatro cosas y un resumen”, La Turbina, no. 2, febrero de 1928, 8-10.

${ }^{26}$ Los Estatutos de la Federación de 1930 contemplaban que las secciones que no hubiesen abonado las cuotas de cuatro trimestres serían dadas de baja, salvo que hubiese motivos justificados.

${ }^{27}$ Jorge Unsaín, "Problema de suma importancia", La Turbina, no . 4, marzo de 1929, 15.

28 "Importante", La Turbina, n'. 5, noviembre de 1929, 5.

${ }^{29}$ CDMH, P-S. Santander 0-141, Actas del V Congreso de la Federación Española de Agua, Gas y Electricidad, Acta de la sesión inaugural celebrada el día 12 de agosto de 1933, 4.
} 
Dictadura $^{30}$, que los colocó en una situación de privilegio respecto de anarquistas y comunistas, que fueron perseguidos. Situación que se tradujo en que el sindicato socialista obtuviera una representación hegemónica en los Comités Paritarios, controlando hasta el $60 \%$ de los representantes de los trabajadores en ellos. Justificó su participación en ese organismo, y en los de representación estatal, aduciendo que no cabía arriesgar la existencia de los sindicatos y la legislación social para defender un sistema parlamentario que había servido a los intereses de la oligarquía ${ }^{31}$.

Jorge Unsaín, en el nº 1, de julio de 1927, lo abordó en "Intervención en la vida política del Estado y del Municipio”. Destacó que el hecho de que el socialismo, al no haber tenido representación en las Cortes y los municipios durante la Restauración, había permitido que los "los huelguistas llenasen las cárceles". Recordó que en el Segundo Congreso de la Federación de 1926 se acordó la intervención de las secciones en la vida política del Estado, incluidos los municipios. Por último, señaló que la participación en la vida política por compañeros de otros países había logrado la municipalización de servicios públicos ${ }^{32}$.

En el mismo número, V. Marco Camilleri, en “Mi Opinión”, defendió los Comités paritarios. A propuesta del Ministro Trabajo, Eduardo Aunós Pérez, se aprobó el Decreto de 26 de noviembre de 1926 que creó la Organización Corporativa Nacional, formada por diversos organismos, entre ellos los Comités Paritarios locales, cuya finalidad era "determinar las condiciones de reglamentación del trabajo de su oficio o profesión, prevenir los conflictos industriales, e intentar su resolución si llegaran a producirse, resolver las diferencias particulares que entre patronos y obreros se

\footnotetext{
${ }^{30}$ Sobre el PSOE durante la Dictadura de Primo de Rivera, véase, entre otros, la obra de Ramón Alquézar y Josep Tormes, Historia del socialismo español. Tomo 2. 1900-1931 (Barcelona: Conjunto Editorial, 1989).

${ }^{31}$ Enrique de Santiago, La U.G.T. ante la Revolución (Madrid, 1932), 26. María Cruz Seoane y María Dolores Sáiz García, Historia del periodismo en España..., 364-365. El 31 de marzo de 1924, el PSOE y la UGT acordaron intervenir en la vida política a través de las instituciones de la Dictadura. Y, tras la publicación del Decreto-ley que creó la organización corporativa nacional, la UGT envió una circular a sus secciones recomendándoles que solicitasen la creación de Comités Paritarios en sus respectivos oficios, lo que le sirvió para recupera su actividad y, gracias a ello, aumentar la afiliación. Javier Aisa y V. M. Arbeloa, Historia de la Unión General de Trabajadores (U.G.T.) (Bilbao: Edita ZERO, 1975), 106-107 y 111-112. Enrique Moral Sandoval, "El socialismo y la Dictadura de Primo de Rivera" coord.. por Santos Juliá Díaz, El socialismo en España: desde la fundación del PSOE HASTA 1975 (Madrid: Editorial Pablo Iglesias, 1986). Ángeles Finque Jiménez, "La intervención del socialismo en la Dictadura de Primo de Rivera (1923-1930)" (Tesis doctoral, Universidad Autónoma de Madrid, 2009).
}

${ }^{32}$ La Turbina, $\mathrm{n}^{\circ}$. 1, julio de 1927, 12-13. 
suscitasen, organizar Bolsas de Trabajo y realizar cualesquiera otras funciones sociales redundantes en provecho de la profesión respectiva"33. Lo constituían cinco representantes de los obreros, elegidos por las asociaciones legales, e igual número por los patronos, más un presidente y un vicepresidente designados por el gobernador civil. En el artículo explicó que la finalidad de los Comités Paritarios era resolver las desavenencias sin que fuesen necesarios huelgas y motines, en los que sólo podían tener representantes los sindicatos reconocidos, de ahí que animaba a la afiliación a las secciones de la Federación: "Entrad de lleno en la Agrupación y tendréis derecho a todo; fuera de ella o no lo tenéis a nada" 34 .

En el $\mathrm{n}^{\circ}$. 2, de febrero de 1928, Ricardo Moledo, miembro de la Sección de Madrid, en "Memoria de la Sección de Madrid", puso el foco de atención en la problemática surgida tras la constitución de una "Asociación", promovida por las empresas para evitar que su sección tuviese representación en los Comités Paritarios. La elección de los miembros de los Comités Paritarios que representaba a los trabajadores se hacía mediante unas elecciones en las que, como hemos comentado, solo podían participar las candidaturas de los sindicatos legales. Explicó la forma de proceder de los empresarios, primero, la dirección de una de las empresas más poderosas, no daba su nombre, adelantamos que se trataba de Unión Eléctrica Madrileña, se había dirigido al Ministerio de Trabajo exigiendo la excepción para las industrias comprendidas en la Federación, aduciendo que ya funcionaba una comisión de conciliación y arbitraje que realizaba las mismas tareas que los Comités Paritarios. La Federación respondió presentando un recurso ante la Comisión de Corporaciones del Ministerio de Trabajo, argumentado que se trataba de un sindicato constituido por las compañías para evitar que los obreros tuviesen representación, no prosperó, la Comisión lo reconoció como sindicato. La sección madrileña reaccionó organizando varios actos de propaganda. A su vez, la empresa respondió con la suspensión de empleo de varios de los miembros de la Sección de Madrid ${ }^{35}$.

\footnotetext{
${ }^{33}$ Gaceta de Madrid, 26 de noviembre de 1926.

${ }^{34}$ La Turbina, $\mathrm{n}^{\mathrm{o}}$. 1, 13-14.

${ }^{35}$ La Turbina, $\mathrm{n}^{\circ}$. 2, febrero de 1928, pp. 3-4. Sobre este asunto, también puede consultarse el $\mathrm{n}^{\circ} .3$, septiembre de 1928, y el artículo de José Cabeza, "Industrias de Agua, Gas y Electricidad", Almanaque de El Socialista para 1933, Madrid, 205-206.
} 
La revista informó acerca del mitin organizado por la Sociedad de Gasistas, Electricistas y Similares de Madrid (SGEM), celebrado en la Casa del Pueblo el 2 de diciembre de 1928, con la finalidad de concienciar a los trabajadores de la necesidad de elegir la candidatura del sindicato en las elecciones para los Comités Paritarios previstas para las próximas semanas. El Secretario de la Sociedad de Gasistas y Electricistas, del que no se dice su nombre, señaló a Unión Eléctrica Madrileña ${ }^{36}$ como la compañía que se había mostrado especialmente beligerante con los comités, creando una "Asociación" para que suplantase la representación de los obreros en los comités, cuyas reuniones se celebraban en las dependencias de la empresa. Explicó que la eléctrica había hecho circular a sus empleados una "hoja" apoyando el voto a la candidatura de la «Asociación». Además, la acusó de que, a diferencia de otras compañías, no transigía con el sindicato. Igualmente, le recriminó que había concebido diversos organismos, entre ellos la "Comisión de informe y conciliación" para que los trabajadores no contactasen con la SGEM.

Al respecto, cabe mencionar que los trabajadores del sector eléctrico en Madrid constituían una élite dentro de la clase trabajadora, sus condiciones laborales en el periodo de entreguerras fueron especialmente buenas en comparación con el resto ${ }^{37}$. El salario era superior a la media y percibían un mínimo de días de vacaciones pagadas, una remuneración extraordinaria por Navidad, cobro de salario cuando el empleado enfermase, un sistema de pensiones generoso, rebaja en las tarifas eléctricas, participación en los beneficios y acceso al economato de manera gratuita, bibliotecas, escuelas, asistencia médica, farmacéutica y hospitalaria. Esto fue el resultado de la

\footnotetext{
${ }^{36}$ En 1912 se constituyó Unión Eléctrica Madrileña, a partir de la Compañía General Madrileña de Electricidad, la Sociedad de Gasificación Industrial y Salto de Bolarque, estos últimos controlados por el Banco Urquijo. Luis Enrique Otero Carvajal y Nuria Rodríguez Martín, "Infraestructuras urbanas y modernidad. Madrid, nuevas necesidades y nuevos servicios en una metrópoli moderna, 1900-1936", Historia Contemporánea, 59 (2019), 39-40.

${ }^{37}$ Germán de la Mora directivo de las eléctricas madrileñas, afirmó que los sueldos de los empleados de las eléctricas en Madrid eran de los más elevados del país en dicho sector y similares a los de ciudades de igual categoría del extranjero. Germán de la Mora, 26 años de lucha en la industria eléctrica de Madrid, 1900-1936 (s.1. [Segovia]: Establecimiento Tipográfico El Adelantado de Segovia, 1937). En ese folleto explica las prácticas de bienestar industrial implementadas por las eléctricas madrileñas. La información proporcionada por una estadística del Ministerio de Trabajo y Previsión publicada en 1931 y referida a los años 1914 a 1925, confirma que los salarios del sector eléctrico madrileño estuvieron entre los más altos de España. Ministerio de Trabajo y Previsión, Estadística de los Salarios y Jornadas de Trabajo referida al periodo 1914-1930 (Madrid: Imprenta y Encuadernación de los Sobrinos de la Sucesora de M. Minuesa de los Ríos, 1931), LXXX.
} 
apuesta decidida de las compañías eléctricas por prácticas de bienestar industrial para sus obreros. Una vez que el mercado de distribución de electricidad se consolidó ${ }^{38}$, la actitud de las direcciones de las empresas hacia los trabajadores pasó de la colisión a la cooperación, con la que pretendían dejar fuera a los sindicatos de clase. Dicha estrategia también se debió a que había más de una eléctrica en Madrid, lo que confirió a los empleados mayor capacidad de negociación, en el periodo aquí estudiado existían dos grandes empresas, la mencionada Unión Eléctrica Madrileña y la Sociedad Hidroeléctrica Española a través de su filial Cooperativa Electra Madrid ${ }^{39}$.

Santiago Pérez afirmó que los Comités Paritarios habían sido creados con la intención de favorecer más a los patronos que a la clase obrera. Pese a ello, consideró que también beneficiaban a los empleados puesto que, gracias a la Organización Corporativa, las organizaciones obreras podían tener personalidad jurídica. Asimismo, porque les permitía discutir con las compañías sobre los siguientes asuntos: contrato de trabajo que incluía el salario, bolsas de trabajo y comisiones inspectoras encargadas de vigilar el cumplimiento de los acuerdos de los Comités Paritarios. Pidió el voto a la candidatura del sindicato y afirmó: "El que vote la candidatura de la Empresa es porque es adepto a ella o por miedo a las represalias".

Andrés Saborit, miembro de la Comisión de Corporaciones, justificó su participación en dicho organismo, aduciendo que era el encargado de resolver sobre los asuntos en los que los Comités Paritarios no llegaban a un acuerdo. Lo mismo planteó en relación a la participación de la S.G.E.M. en los Comités Paritarios y rechazó las críticas de colaboracionismo: "[...] no hacemos el juego sucio de colaboración al reconocer que en la ley de Comités paritarios hay principios esenciales que coinciden con nuestros puntos de vista" 40 .

\footnotetext{
${ }^{38}$ En Madrid las eléctricas lograron que el consumo de electricidad por habitante fuese superior al de París y Roma, gracias al gran desarrollo del alumbrado privado. Anna María Aubanell Jubany "La competencia en la distribución de electricidad en Madrid, 1890-1913", Revista de Historia Industrial, 2 (1992), 168-170. https://doi.org/10.1344/rhi.v0i2.18174. Luis Enrique Otero Carvajal y Nuria Rodríguez Martín, "Infraestructuras urbanas...", 38 y 41-42.

39 Anna Maria Aubanell Jubany, "La elite de la clase trabajadora. Las condiciones laborales de los trabajadores de las eléctricas madrileñas en el periodo de entreguerras", Scripta Nova. Revista Electrónica de Geografia y Ciencias Sociales, vol. VI, 119 (2002). http://www.ub.es/geocrit/sn/sn119-17.htm

40 "Mitin que, organizado por Sociedad de Gasistas y Electricistas, de Madrid, se celebró en la Casa del Pueblo el día 2 de diciembre de 1928", La Turbina, no . 4, marzo de 1929, 2-11.
} 
Lo sucedido en Madrid con la Unión Eléctrica Madrileña no fue un caso aislado. En Valencia, las empresas procedieron de la misma manera, crearon una «Asociación» que fue derrotada en las elecciones de los Comités Paritarios ${ }^{41}$. Asimismo, despidieron a gran número de obreros, incluidos vocales del comité paritario de gas, electricidad y agua $^{42}$. En marzo de 1929, La Turbina informó de los lugares en los que las candidaturas de la Federación habían salido victoriosas recientemente: Almería, Bilbao, Burgos (electricistas), Burgos (gasistas), Burgos (aguas), Castellón, Madrid (gas), Madrid (electricidad), Madrid (aguas), Oviedo (electricistas), Oviedo (gasistas), Oviedo (aguas), Palencia, Toledo y Zaragoza (gasistas) ${ }^{43}$.

Si bien la tónica dominante fue la defensa de los Comités Paritarios ${ }^{44}$, cabe mencionar por su excepcionalidad, el artículo de Joaquín Moya, "Los Comités paritarios", $\mathrm{n}^{\mathrm{o}} .5$, de noviembre de 1929, en el que criticó duramente su funcionamiento en los siguientes términos: "Más el desengaño sufrido es patente, y de continuar así, de seguro que los vocales obreros en los organismos paritarios se verán en la necesidad de dimitir de sus cargos, porque la labor que realizan resulta estéril, salvo raras excepciones". Explicó el lento proceder de los comités, los cuales se reunían sólo una vez al mes si había asuntos graves. Se presentaban proposiciones, si no las resolvían en la primera reunión, luego solía nombrarse una ponencia para que dictaminase. El resultado: tres meses para una resolución. Por todo ello, propuso la modificación de la normativa en el sentido de que otorgase mayores atribuciones a los vocales y al Comité, así como regular que el tiempo de respuesta del comité paritario fuese menor ${ }^{45}$.

En el siguiente número, el 6, de julio de 1930, seguramente para contrarrestar esta imagen negativa acerca de la eficacia de los Comités Paritarios, se dio a conocer la sentencia del comité paritario de gasistas, electricistas, aguas y similares de Madrid del

\footnotetext{
${ }^{41}$ La Turbina, $\mathrm{n}^{\mathrm{o}} .3$, septiembre de 1928, p. 2.

42 José Cabeza Temblas, "Documento elevado por la Federación Nacional de Obreros de las Industrias de Gas, Electricidad, Aguas y Similares de España al ministro de Trabajo y Comisión Permanente de Trabajo", fechado el 1 de noviembre de 1931, La Turbina, nº. 7, enero de 1930, 14.

${ }^{43}$ La Turbina, $\mathrm{n}^{\circ} .4$, marzo de 1929, p. 21.

${ }^{44}$ Lo mismo defendió el Boletín de la Sociedad General de Obreros Gasistas, Electricistas, Teléfonos, Aguas y Similares de Madrid, la Sección de Madrid de la Federación, del que sólo hemos localizado un número de 1928.

45 Joaquín Moya, "Los Comités paritarios", La Turbina, nº. 5, noviembre de 1929, 15.
} 
18 de noviembre de 1929, respecto de la demanda planteada por Manuel Martín Zapatero contra Unión Eléctrica Madrileña por haber sido despedido de su puesto de lector de contadores. Martín Zapatero presentó un escrito a dicho comité el 25 de octubre de 1929 en el que expuso que, siendo lector de contadores con contrato fijo de esa compañía, había sido despedido tres días antes con argumentos falsos, por lo que pedía la readmisión o la indemnización que le correspondiese. El 5 de noviembre tuvo lugar el acto de conciliación, en el que la empresa afirmó que el empleado había faltado al respeto y desobedecido a sus jefes, lo que negó el demandante, sin que llegasen a un acuerdo. A continuación, se fijó el 9 de noviembre para la celebración del juicio ante la Ponencia-Tribunal de despidos.

En el juicio el trabajador presentó un escrito de ampliación de la demanda en el que expuso que el despido le causaba grave perjuicio ya que cuando se decidió cobraba 6,94 pesetas al día, una mensualidad por gratificación de Navidad, y dos mensualidades y media por participación de beneficios al año. Que el despido, a su parecer, injusto, también le perjudicaba por su edad, 46 años, límite señalado generalmente para ingresar en las eléctricas, las cuales además eran un número reducido en Madrid, por lo que sus posibilidades de encontrar empleo en ese sector eran inexistentes. Asimismo, se ratificó en que las acusaciones de la compañía no eran ciertas, todo lo contrario, como demostraba el hecho de que hubiese sido ascendido recientemente. Por su parte, la eléctrica presentó el informe elaborado por el jefe superior del demandante, en el que afirmó que éste no cumplía con sus obligaciones. La Federación afirmó que la Unión Eléctrica le despidió porque "molestaba a la empresa por su actuación”, lo que parece indicar que actuó como sindicalista ${ }^{46}$.

La Ponencia falló en contra de la compañía a la que ordenó la readmisión del trabajador y el pago a este de los ingresos que había dejado de percibir desde el despido. Si la empresa no quisiese readmitir al obrero, debería abonarle, además de dichos ingresos, una indemnización por el tiempo que tardase en un lograr nuevo empleo de “cuatro decenas de jornal". Entre la presentación de la demanda y el falló de la Ponencia

\footnotetext{
${ }^{46}$ José Cabeza Temblas, "Documento elevado por la Federación Nacional de Obreros de las Industrias de Gas, Electricidad, Aguas y Similares de España al ministro de Trabajo y Comisión Permanente de Trabajo", fechado el 1 de noviembre de 1931, La Turbina, nº. 7, enero de 1930, 14.
} 
transcurrió poco más de un mes, lo que cuestiona la idea planteada por Joaquín Moya de que los comités eran lentos en la resolución de los asuntos ${ }^{47}$.

Los Comités Paritarios fueron sustituidos por los Jurados Mixtos mediante la Ley de 27 de noviembre de 1931, que les confirió las atribuciones de "regular la vida de la profesión o profesiones y de ejercer funciones de conciliación y arbitraje" y determinar "para cada oficio o profesión las condiciones generales de reglamento del trabajo, salarios, fijación del plazo mínimo de duración de los contratos, horarios, horas extraordinarias, formas y requisitos de los despidos".

Su composición era similar a la de los Comités Paritarios, con igual número de representantes de los obreros y la patronal, elegidos en unas elecciones a las que solo se podrían presentar las candidaturas de sindicatos y empresas legalmente reconocidos. Los presidentes y vicepresidentes de los jurados serían propuestos por empleados y patronos, si no hubiese acuerdo entre ambas partes, el Ministerio de Trabajo los designaría ${ }^{48}$.

Antes de aprobarse esta ley, el secretario del Comité Nacional de la Federación, José Cabeza Temblas $^{49}$ presentó un escrito a dicho ministerio, en nombre del Comité de la Federación, fechado el 1 de noviembre de 1931, en el que solicitó se incluyese en la ley que el Gobierno estaba elaborando que, si el jurado mixto declaraba improcedente el despido, la empresa fuese condenada a la readmisión o una indemnización de 1.000 pesetas por año de servicio, y que no fuera la compañía, sino el trabajador, el que decidiese lo que mejor le conviniese. Esto indica que el sindicato era partidario de los Jurados Mixtos ${ }^{50}$, si bien mejorando las consecuencias del despido cuando fuese declarado improcedente. La solicitud no fue considerada, en la ley se estableció que si el despido era improcedente, el patrono

\footnotetext{
47 "Sentencia del Comité Paritario de Gasistas, Electricistas, Aguas y Similares, en la demanda de despido de Manuel Martín Zapatero”, La Turbina, nº, 6, septiembre de 1930, 27-29.

${ }^{48}$ Gaceta de Madrid, 28 de noviembre de 1931.

${ }^{49}$ En el IV Congreso de la Federación, celebrado los días 12 a 17 de agosto de 1933, en Madrid, se renovó el Comité Nacional, cuyos puestos principales recayeron en: José Alonso (presidente), vicepresidente (Manuel Ferrezuelo), José Cabeza Temblas (secretario), vicesecretario-contador (Francisco Sánchez Berihuete) y José Díaz Hervás (Tesorero). Más adelante analizaremos las críticas que el Comité recibió por parte de diversas secciones, en especial la de Madrid.
}

${ }^{50}$ Manuel Redero San Román, Estudios de Historia, .... 
tendría la opción de readmitirlo o abonarle la indemnización fijada por el presidente del jurado mixto ${ }^{51}$.

La Federación persistió en su petición, realizó varias visitas al Ministro de Trabajo, Francisco Largo Caballero, a la sazón secretario general de la Unión General de Trabajadores, presentándole escritos y, el secretario, a instancias de la organización, impartió conferencias sobre el asunto. Todo ello finalmente dio sus frutos, Largo Caballero promovió el decreto de 23 de agosto de $1932^{52}$ que anuló el mencionado derecho de elección de las empresas entre la readmisión y la indemnización quedando obligadas a readmitir al trabajador y a abonarle el salario que le correspondiese desde el despido, normativa que afectaría a las compañías de servicios públicos, entre ellas se contemplaba a las de aguas, gas y electricidad, incluidas las de propiedad pública, la banca y las que en la fecha de la promulgación de esa disposición tuviesen establecidas mediante bases o reglamentos de trabajo la condición de que para el despido sería necesario la elaboración de expedientes en los que se justificase las faltas que habían llevado a la pérdida del trabajo ${ }^{53}$.

\section{LA ESCISIÓN EN LA FEDERACIÓN}

A partir del no .7 , de julio de 1932, fue recurrente el tema de la escisión que tuvo lugar en la Sección de Madrid y la baja de varias secciones de la Federación, según esta organización, provocadas por los anarquistas.

José Cabeza Temblas en el artículo «Los anarcosindicalistas de nuestras industrias», los acusó de ser violentos, denominándolos «los del pistolón», a los que preguntaba de manera retórica dónde estaban cuando en la capital, tras haberse acordado un contrato de trabajo, a su parecer, "muy malo", sus afiliados recurrieron a la secretaría de la sección madrileña para que les defendiera en el jurado mixto.

\footnotetext{
${ }^{51}$ José Cabeza Temblas, "Documento elevado por la Federación Nacional de Obreros de las Industrias de Gas, Electricidad, Aguas y Similares de España al ministro de Trabajo y Comisión Permanente de Trabajo", fechado el 1 de noviembre de 1931, La Turbina, no. 7, enero de 1930, 14-15.

52 Gaceta de Madrid, 25 de agosto de 1932.

53 "Decreto de 23 de agosto sobre el despido injusto", La Turbina, n. 9, febrero de 1933, 1-2.
} 
En Málaga, el intento de separación protagonizado por los anarquistas había fracasado $^{54}$. Lo sucedido en Madrid fue más grave ya que la escisión se materializó, se trataba de la sección más importante de la Federación, a principios de 1933 reunió al $47,6 \%$ del total de los afilados ${ }^{55}$. José Cabeza afirmó que los militantes de esa sección que la habían abandonado eran gentes poco valiosas que solían "vociferar en las juntas generales". Lo preocupante es que habían formado su propia organización, señaló a Crispín Álvarez, al que acusó de avenirse siempre a lo ordenado por su empresa y de formar parte del "sindicato" creado por Unión Eléctrica Madrileña ${ }^{56}$.

En el nº. 9, de febrero de 1933, Cabeza firmó el artículo "Cómo son los destacados anarcosindicalistas de nuestras industrias”, en el que señaló a D. Antonio, vocal de la Junta directiva de la Sección de Madrid, como el promotor de la escisión que había intentado constituir una federación anarcosindicalista. José Cabeza fue acusado por C. Álvarez, antiguo afiliado, de recibir un pago desorbitado por los cargos desempeñados. Cabeza se defendió explicando las tareas que desarrollaba, el tiempo de trabajo que le requerían y el gasto que le suponían, superior a la gratificación que le daba la organización. Acusó a Álvarez de tener dos empleos, uno de ellos obtenido en el Ayuntamiento de Madrid durante la Dictadura de Primo de Rivera. También dijo que cuando él ocupó el cargo de presidente de la sección madrileña, Álvarez le dijo "Mire usted, Cabeza, debo no sé cuántos cupones, y no quisiera que me hubieran dado de baja, porque yo deseo continuar en la sociedad". Le permitió que los abonase, sin embargo, poco después, se retrasó de nuevo en los $\operatorname{pagos}^{57}$.

\footnotetext{
${ }^{54}$ En el V Congreso de la Federación, celebrado los días 12 a 17 agosto en la capital, la sección de Madrid, con el apoyo de la de Málaga, manifestaron su oposición a la Memoria presentada por el Comité, aduciendo que en la misma no se abordaban temas importantes, como el de los Jurados Mixtos, ni se ofrecían datos estadísticos, pero sí se decía que La Turbina no se publicaba porque "no quieren escribir los que saben hacerlo", cuando la realidad era, según su parecer, que "muchos camaradas han tenido que retirar sus artículos porque no se los publican". También porque en la Memoria se trataba a la sección madrileña "de traidores encubiertos y malos compañeros". Centro Documental de la Memoria Histórica (CDMH), P-S. Santander 0-141, Actas del V Congreso de la Federación Española de Agua, Gas y Electricidad, Acta de la tercera sesión celebrada en la tarde del 13 de agosto, 1-2.

${ }^{55}$ La Turbina, $\mathrm{n}^{\circ}$. 10, julio de 1933.

56 José Cabeza Temblas, "Los anarconsindicalistas de nuestras industrias", La Turbina, no. 7, enero de 1932, 5-6.

57 José Cabeza Temblas, “Cómo son los destacados anarcosindicalistas de nuestro tiempo?”, La Turbina, $n^{\circ} .9$, febrero de 1933, pp. 26-31.
} 
En el $n^{\circ}$. 10, de julio de 1933, el último que se publicó, Juan Alonso y José Cabeza, presidente y secretario respectivamente del Comité, firmaron "Memoria", con el que quisieron justificar la labor desarrollada por el Comité Nacional desde 1930. En ese texto abordaron la grave crisis que sufrió la Federación, cuya máxima expresión fue que la sección madrileña dejó de estar controlada por aquella y la baja de varias secciones, como consecución de la intervención de anarquistas, en concreto de la $\mathrm{CNT}^{58}$, que parece ser pretendieron hacerse con el control de la Federación y de secciones. Según este artículo, la crisis en la Sección de Madrid se manifestó de diversas maneras, el secretario de la Federación dejó de ser su presidente, también quedaron sin sus cargos los demás miembros del Comité Nacional. Esto indicaría que la lucha por el poder se había dilucidado con la salida de los miembros de la Federación de la Sección Madrileña, o al menos de sus cargos. La Sección de Madrid cambió su domicilio social a otro lugar, es decir, dejó de compartirlo con la Federación.

Continuaron afirmando que desde la nueva directiva de la Sección de Madrid se lanzó una campaña de desprestigio contra la Federación que, en parte, dio resultado. La Sección de Almería se dio de baja en la organización, pasó a estar controlada por los "sindicalistas", con ellos se refiere a la Confederación Nacional del Trabajo, la Federación creó una nueva sección. Lo mismo sucedió con la de Vigo. Los anarquistas también intentaron crear una Federación regional para las secciones de Galicia con el propósito de controlarlas, parece que sin éxito.

Asimismo, Juan Alonso y José Cabeza expusieron su opinión acerca de las discrepancias con algunas secciones. El origen de la disputa tuvo dos causas. La primera, con motivo del nombramiento de vocal para el Consejo de Trabajo, los miembros del Comité designaron por unanimidad a Cabeza como representante de la Federación, decisión que fue aceptada por el Comité Nacional de la Unión General de Trabajadores, lo que disgustó a la sección madrileña. De ahí que la UGT hiciese un llamamiento a la disciplina de voto para cuando tuviesen lugar las elecciones para elegir representantes en el Consejo del Trabajo, como sigue: "los votos que no vayan a favor del candidato propuesto son votos perdidos, que no pueden tener más consecuencias que

\footnotetext{
58 Sobre las desavenencias entre el sindicato socialista y la Confederación Nacional del Trabajo, puede consultarse Redero San Román, Estudios de Historia,...,46.
} 
mermar el prestigio de la Unión General de Trabajadores de España". Pese a ello, Manuel Ruiz Porras, vocal de la Sección de Madrid, siguiendo las directrices de la Sección de Madrid, se postuló.

La segunda surgió a raíz de que el Comité Nacional solicitase a la sección madrileña ayuda para la secretaría, debido a que el crecimiento de la Federación conllevaba más trabajo administrativo. El Comité propuso dos nombres a la Sección de Madrid que ésta no aceptó, sino que eligió otras dos personas, una de ellas “jamás ocultó su simpatía por la Confederación Nacional del Trabajo, aunque estaba dentro de nuestra organización". Tras esa elección y como había noticias de que en algunas secciones, como la de Almería, simpatizantes de la Confederación habían pasado a controlarlas, no se quiso consentir que también se infiltrasen en el Comité. Por todo ello, el Comité respondió a la sección madrileña que le agradecía su propuesta, pero que se había reorganizado el trabajo, no siendo necesaria su ayuda. El resultado es que

simpatizantes encubiertos de la Confederación Nacional del Trabajo y los afiliados directamente a la misma comenzaron una campaña de injurias y acusaciones falsas, principalmente, y con gran saña, contra el secretario, al que culpaban, quizá acertadamente, de ser el autor de la destrucción de su maniobra para llegar hasta el Comité de la Federación ${ }^{59}$.

Según Alonso y Cabeza, el Comité Nacional no debía dar cuentas de su gestión a la dirección de la Sección de Madrid, como algunos compañeros habían exigido, sólo tenía que hacerlo ante el Congreso de la Federación. Señalaron a Ruiz Porras como responsable de dicha exigencia, quien abandonó el Comité. A continuación, la sección madrileña decidió trasladar su domicilio social que hasta entonces había compartido con la Federación, aduciendo que en la "Secretaría de la Casa del Pueblo era materialmente imposible trabajar".

El siguiente desencuentro vino dado porque el Comité decidió aplazar la celebración del siguiente Congreso, argumentado que la situación financiera de la

\footnotetext{
${ }^{59}$ Cabeza también defendió su gestión como secretario de la Federación en su V Congreso, C.D.M.H., PS. Santander 0-141, Actas del V Congreso de la Federación Española de Agua, Gas y Electricidad, Acta de la tercera sesión celebrada en la tarde del día 13 de agosto de 1933, 4.
} 
organización lo aconsejaba. El tesorero, José Díaz Hervás, cuantificó el déficit de la Federación que se encontró el nuevo Comité elegido en el IV Congreso celebrado en 1930 en más de 2.000 pesetas $^{60}$. Seguramente el motivo real fue el temor de que en dicho evento la Sección de Madrid, recuérdese la más numerosa, tomase el control de la organización. Prueba de ello es que ésta ofreció gratis a la Federación su local para la celebración del Congreso y que cuando se celebró se puso de manifiesto la oposición entre la sección madrileña y el Comité. Propuesta a lo que se opuso el Comité con éxito ${ }^{61}$.

Los Estatutos de la Federación aprobados en 1930 daban la razón al Comité en su decisión de aplazar el Congreso. El Capítulo 4 de los mismos regulaba la periodicidad y organización de los congresos en los siguientes términos. Los ordinarios se celebrarían cada dos años, en ellos se examinaría la gestión del Comité Nacional y se solventarían las propuestas presentadas por las secciones. El Comité podría posponer su celebración si las circunstancias lo recomendasen. Habría congreso extraordinario cuando lo solicitasen la mayoría de las secciones o el Comité lo estimase necesario ${ }^{62}$.

Según la Memoria de Alonso y Cabeza, la propuesta presentada por el Comité para aplazar el Congreso fue aceptada por la mayoría de las secciones mediante un referéndum. Ambos reconocieron que la Federación había recibido misivas de las secciones de Valladolid, Valencia y Burgos criticando al Comité y exigiendo la celebración del Congreso ${ }^{63}$. Lo que no dijeron es que la propuesta del Comité solo ganó por 4 votos de diferencia ${ }^{64}$, lo que muestra la división existente en la organización.

\footnotetext{
${ }^{60}$ José Díaz Hervas, “Tesorería”, La Turbina, no. 7, enero 1932, 4-5.

${ }^{61}$ C.D.M.H., P-S. Santander 0-141, Actas del V Congreso de la Federación Española de Agua, Gas y Electricidad, Acta de segunda sesión celebrada en la tarde del 12 de agosto, p. 4: "Moreno de la Sección Madrid pone a disposición del Congreso los locales de esta para que se reúnan las Ponencias. Cabeza estima que las Ponencias deben reunirse en el local del Congreso». Por su parte, la Sección de Madrid en dicha sesión manifestó que el Comité debería haber convocado el Congreso tras la caída de la Dictadura de Primero de Rivera y que el argumento del Comité de que no había fondos no era válido ya que "otros Congresos se habían celebrado sin dinero".

${ }^{62}$ La Turbina, $\mathrm{n}^{\mathrm{o}}$. 7, enero de 1932.

${ }^{63}$ Juan Alonso y José Cabeza Temblas, "Memoria”, La Turbina, nº. 10, julio de 1933, 1-15.

${ }^{64}$ C.D.M.H., P-S. Santander 0-141, Actas del V Congreso de la Federación Española de Agua, Gas y Electricidad, Acta de la tercera sesión celebrada en la tarde del día 13 de agosto de 1933, 5.
} 
Los miembros de "Ponencia de Conflictos" del mencionado V Congreso de la Federación, constituida por Pedro Mirás, Joaquín Moya, Emilio Cobos, Leandro Larumbe y Fernando Rodríguez, redactaron un documento en el que concluyeron lo siguiente: 1. El Comité tenía la potestad contemplada en los mencionados Estatutos de posponer el Congreso. Ahora bien, consideraron que si bien la situación económica del sindicato no era buena, había asuntos relevantes que hubiesen aconsejado la celebración del mismo; 2. Rechazó el intento de la Sección de Madrid de desautorizar al Comité; y, 3. Consideró que el procedimiento seguido por el Comité para la elección de vocal para el Consejo de Trabajo había sido correcto ${ }^{65}$.

En la página 29 del último número de la revista se incluyó el siguiente texto: "Que la Sección de Agua, Gas y Electricidad de Madrid ve con disgusto la trayectoria que se imprime al boletín de la Federación, La Turbina, empleándolo como tribuna política y para dilucidar cuestiones personalísimas". En definitiva, hubo una lucha por el poder que se saldó finalmente con la desaparición de la publicación. Como se ha mencionado al inicio de este estudio, la documentación localizada para la Guerra Civil sobre la Federación muestra que finalmente salieron victoriosos los partidarios de la Unión General de Trabajadores.

\section{CONCLUSIONES}

Al no haberse apenas conservado documentación primaria de la Federación Nacional de Obreros de la industria del Gas, Electricidad y Similares tales como actas, memorias, correspondencia, etc., salvo las Actas del V Congreso, su órgano de expresión, la revista La Turbina, ha resultado ser una fuente imprescindible para su estudio. Este órgano de prensa se publicó entre los años 1927 y 1933, situándose por tanto entre dos periodos muy distintos de la historia de España —Dictadura Primorriverista y Segunda República - en cuanto a las cuestiones aquí tratadas que atañen a los derechos y las libertades sindicales.

\footnotetext{
${ }^{65}$ C.D.M.H., P-S. Santander 0-141, Actas del V Congreso de la Federación Española de Agua, Gas y Electricidad, Al V Congreso de la Federación de Industria de Agua, Gas y Electricidad de España. Ponencia de conflictos.
} 
El vaciado y estudio exhaustivo de los contenidos de todos los números de La Turbina nos ha permitido documentar y analizar las principales preocupaciones de la Federación, organización obrera que hasta la fecha no había recibido atención por parte de la historiografía. Dichas preocupaciones giraron principalmente en torno a la relativa debilidad de la organización. Asimismo, acerca de su posicionamiento respecto de los Comités Paritarios y los Jurados Mixtos que fue, como era previsible teniendo en cuenta que dependía de la UGT y su afinidad con el PSOE, favorable a dichos organismos en los que vieron un instrumento de mejora de las condiciones laborales de los trabajadores.

Además, se han mostrado también en este trabajo las disputas con los anarquistas que intentaron hacerse con el control del sindicato, una lucha que provocó una profunda crisis que a punto estuvo a punto de provocar la desaparición de la organización, y que, en todo caso, sí ocasionó el fin de la revista La Turbina a los siete años de su aparición.

\section{BIBLIOGRAFÍA}

Aisa, Javier y Arbeloa, V. M. Historia de la Unión General de Trabajadores (U.G.T.). Bilbao: Edita ZERO, 1975.

Alquézar, Ramón y Tormes, Josep. Historia del socialismo español. Tomo 2. 19001931. Barcelona: Conjunto Editorial, 1989.

Aubanell Jubany, Anna María. "La elite de la clase trabajadora. Las condiciones laborales de los trabajadores de las eléctricas madrileñas en el periodo de entreguerras". Scripta Nova. Revista Electrónica de Geografía y Ciencias Sociales, vol. VI, 119, (2002). http://www.ub.es/geocrit/sn/sn119-17.htm

Aubanell Jubany, Anna María. "La competencia en la distribución de electricidad en Madrid, 1890-1913". Revista de Historia Industrial, 2, (1992): 143-171. https://doi.org/10.1344/rhi.v0i2.18174

Bernalte Vega, María Francisca, Fontecha Pedraza, Antonio y Gibaja Velázquez, José Carlos. "Cultura popular madrileña durante la dictadura: el mundo obrero socialista 1923-1930”. En La sociedad madrileña durante la Restauración, editado por Ángel Bahamonde y Luis Enrique Otero Carvajal, 541-560. Madrid: Comunidad de Madrid, 1989.

Bizcarrondo, Marta. Historia de la UGT. Vol. 3. Entre la democracia y la revolución, 1931-1936. Madrid: Siglo XXI, 2008. 
Dorado Fernández, Carlos. "Publicaciones obreras madrileñas, de 1923 al 18 de julio de 1936, en la Hemeroteca Municipal de Madrid”. En Prensa obrera en Madrid, 1855-1936, editado por Santiago Castillo y Luis E. Otero Carvajal, 719-762. Madrid: Comunidad de Madrid-Revista ALFOZ, 1987.

Finque Jiménez, Ángeles. "La intervención del socialismo en la Dictadura de Primo de Rivera (1923-1930)”. Tesis doctoral, Universidad Autónoma de Madrid, 2009.

Gallego, José Andrés. El socialismo durante la dictadura, 1923-1930. Madrid: Tebas, 1977.

Martín, Benjamín. Los problemas de la modernización. Movimiento obrero e industrialización en España. Madrid: Ministerio de Trabajo y Seguridad Social, 1992.

Martín Nájera, Aurelio y González Quintana, Antonio. Fuentes para la Historia de la Unión General de Trabajadores. Madrid: Editorial Pablo Iglesias, 1998.

Martín Ramos, José Luis. Historia de la UGT. Entre la revolución y el reformismo, 1914-1931. Madrid: Siglo XXI, 2008.

Ministerio de Trabajo y Previsión. Estadística de Salarios y Jornadas de Trabajo referida al periodo 1914-1930. Madrid: Imprenta y Encuadernación de los Sobrinos de la Sucesora de M. Minuesa de los Ríos, 1931.

Mora, Germán de la. 26 años de lucha en la industria eléctrica de Madrid 1910-1936. S. 1. [Segovia]: Establecimiento Tipográfico El Adelantado de Segovia, 1937.

Moral Sandoval, Enrique. "El socialismo y la Dictadura de Primo de Rivera". En El socialismo en España: desde la fundación del PSOE hasta 1975, coordinado por Santos Juliá Díaz, 191-211. Madrid: Editorial Pablo Iglesias, 1986.

Otero Carvajal, Luis Enrique y Rodríguez Martín, Nuria. "Infraestructuras urbanas y modernidad. Madrid, nuevas necesidades y nuevos servicios en una metrópoli moderna, 1900-1936", Historia Contemporánea, 59, (2019): 21-57.

Redero San Román, Manuel. Estudios de Historia de la UGT. Salamanca: Ediciones Universidad de Salamanca-Fundación Largo Caballero, 1992.

Sáiz García, María Dolores. "Prensa comunista durante la Dictadura de Primo de Rivera: el proyecto de unidad sindical en 'La Antorcha'. En La prensa de los siglos XIX y XX. Metodología, ideología e información. Aspectos económicos y tecnológicos: I Encuentro de Historia de la Prensa, editado por Carmelo Garitaonandia Garnacho, 245-262. Bilbao: Universidad del País Vasco, 1986.

--. "Prensa socialista durante la dictadura de Primo de Rivera". En Presse et pouvoir en Espagne, editado por Aubert, Paul y Desvois, Jean-Michel, 139-150. Madrid: Maison de Pays Ibériques-Casa de Velázquez, 1996. 
Sánchez Pérez, Francisco. "El movimiento obrero antes de la guerra civil: el enfoque de Manuel Tuñón de Lara". Cuadernos de Historia Contemporánea, 30, (2008): 105-116:

https://revistas.ucm.es/index.php/CHCO/article/view/CHCO0808110105A/6727

Santiago, Enrique de. La U.G.T. ante la Revolución. Madrid, 1932.

Seoane, María Cruz y Sáiz García, María Dolores. Historia del periodismo en España 3. El siglo XX: 1898-1936. Madrid: Alianza, 1996.

Tuñón de Lara, Manuel. "Prensa obrera e Historia contemporánea". En Prensa obrera en Madrid, 1855-1936, editado por Santiago Castillo y Luis E. Otero Carvajal, 23-31. Madrid: Comunidad de Madrid-Revista ALFOZ, 1987.

Vicente Albarrán, Fernando. "Los barrios negros: el Ensanche Sur en la formación del moderno Madrid (1860-1931)". Tesis Doctoral, Universidad Complutense de Madrid, 2011, https://eprints.ucm.es/id/eprint/13957/1/T33443.pdf

--. "Los trabajadores manuales en el Madrid del primer tercio del siglo XX". En Las nuevas clases medias urbanas. Transformación y cambio social en España, 1900-1936, editado por José María Beascoechea Gangoiti y Luis Enrique Otero Carvajal, 100-109. Madrid: Catarata, 2015. 